\title{
Algae Mediated Green Fabrication of Silver Nanoparticles and Examination of Its Antifungal Activity against Clinical Pathogens
}

\author{
Shanmugam Rajeshkumar, Chelladurai Malarkodi, Kanniah Paulkumar, \\ Mahendran Vanaja, Gnanadas Gnanajobitha, and Gurusamy Annadurai
}

\author{
Environmental Nanotechnology Division, Sri Paramakalyani Centre for Environmental Sciences, \\ Manonmaniam Sundaranar University, Alwarkurichi, Tamilnadu 627412, India
}

Correspondence should be addressed to Gurusamy Annadurai; gannadurai@hotmail.com

Received 30 June 2013; Revised 22 August 2013; Accepted 18 November 2013; Published 19 January 2014

Academic Editor: Yuanshi Li

Copyright (C) 2014 Shanmugam Rajeshkumar et al. This is an open access article distributed under the Creative Commons Attribution License, which permits unrestricted use, distribution, and reproduction in any medium, provided the original work is properly cited.

\begin{abstract}
Algae extract has the great efficiency to synthesize the silver nanoparticles as a green route. Brown seaweed mediates the synthesis of silver nanomaterials using extract of Sargassum longifolium. For the improved production of silver nanomaterials, some kinetic studies such as time incubation and $\mathrm{pH}$ were studied in this work. $10 \mathrm{~mL}$ of algal extract was added into the $1 \mathrm{mM} \mathrm{AgNO}_{3}$ aqueous solution. The $\mathrm{pH}$ and reaction time range were changed and the absorbance was taken for the characterization of the nanoparticles at various time intervals, and the high $\mathrm{pH}$ level shows the increased absorbance due to the increased nanoparticles synthesis. The synthesized silver nanoparticles were characterized by Scanning Electron Microscope (SEM) showing that the shape of the material is spherical, and X-Ray Diffraction value obtained from range of (1 111$)$ confirmed synthesized silver nanoparticles in crystalline nature. TEM measurement shows spherical shape of nanoparticles. The Fourier Transmittance Infrared spectrum (FT-IR) confirms the presence of biocomponent in the algae extract which was responsible for the nanoparticles synthesis. The effect of the algal mediated silver nanoparticles against the pathogenic fungi Aspergillus fumigatus, Candida albicans, and Fusarium sp. S. longifolium mediated synthesized silver nanoparticles shows cheap and single step synthesis process and it has high activity against fungus. This green process gives the greater potential biomedical applications of silver nanoparticles.
\end{abstract}

\section{Introduction}

Seaweeds are the natural and renewable living resources in the marine ecosystem and they are consumed for food, feed, and medicine. Seaweeds contain more than 60 elements, macro- and micronutrients, proteins, carbohydrates, vitamins, and aminoacids [1]. Seaweeds are the sources for extracting industrial products such as phycocolloids: carrageenan, alginates, and agar [2,3]. Sargassum is a big family of marine brown algae and it has a broad application field. Most of the seaweeds have the antibacterial activity against pathogenic bacteria like Vibrio parahaemolyticus, Salmonella sp., Shewanella sp., Escherichia coli, Klebsiella pneumoniae, Streptococcus pyogenes, Staphylococcus aureus, Enterococcus faecalis, Pseudomonas aeruginosa, and Proteus mirabilis [4], antibiotic resistant postoperative infectious pathogens [5], and also used as antitumor compounds [6]. Moreover, seaweeds play an important role in adsorption of heavy metals like lead, copper, zinc, and manganese [7].

In the 21st century, nanotechnology is the newly emerging multidisciplinary research area with synthesis of nanosized materials [8]. Nanotechnology is the manipulation and production of materials ranging in size from 1 to 100 nanometer scale [9]. The nanoparticles can play a topmost role in the field of nanomedicines such as health care and medicine diagnostic and screening purposes, drug delivery systems, antisense and gene therapy applications, and tissue engineering and expectations of nanorobots configuration [10]. Many methods adopted in the field of synthesis of nanoparticles are chemical and physical. Nowadays, biological method of 
nanoparticles synthesis is a vast growing technique in the field of nanotechnology [11]. The biological sources had the more quantity of trouble-free protocols and when applied for the human health associated field, it is easy to approach for maintain aseptic environment during the synthesis process of nanoparticles [12]. Recently, biological materials such as bacteria, fungi, plant, and algae were used to synthesis of nanoparticles. Some are Enterobacteria [13], Aspergillus fumigatus [14], Coriander leaf [15], and Sargassum wightii [16] were used to synthesise of nanoparticles. Among the biological materials, algae is called as "bionanofactories" because the live and dead dried biomass was used for synthesis of metallic nanoparticles. It is low cost and environmentally effective, macroscopic structured material, and has the distinct advantage due to its high metal uptake capacity [17]. The rate and size of the nanoparticles were controlled by optimizing the parameters such as $\mathrm{pH}$, temperature, substrate concentration, and incubation time [18].

This study reported that the exposure time and $\mathrm{pH}$ play an important role in the controlling of nanoparticles synthesis by using the S. longifolium algae extract. Nanoparticles synthesis was characterized by UV-vis spectroscopy, crystalline, and morphological structure which were characterized by XRD, SEM, and TEM. The antifungal activity of silver nanoparticles against pathogenic fungus was studied as well.

\section{Materials and Methods}

2.1. Chemicals. Analytical grade chemicals are silver nitrate, sodium hydroxide, and hydrochloric acid used for preparation of silver nanoparticles (NPs) and role of $\mathrm{pH}$ on NPs synthesis. Agar agar, Rose Bengal agar, and Sabouraud Dextrose agar were used for assessment of antifungal activity. All the chemicals and media were purchased from HiMedia (Mumbai, India).

2.2. Collection and Preparation of Algal Extract. The brown algae Sargassum longifolium was collected from the Tuticorin coastal area, Tamilnadu, India. The marine brown seaweed was thoroughly washed with fresh water and distilled water to remove the salt minerals and metallic compounds on the surface of the seaweed. Clean seaweed was dried at a shady place for ten days. The dried leaves were ground into fine powder. $1 \mathrm{gm}$ of algal powder was mixed with $100 \mathrm{~mL}$ of distilled water in the $250 \mathrm{~mL}$ Erlenmeyer flask and boiled at $60^{\circ} \mathrm{C}$ for $10 \mathrm{~min}$. The boiled extract was filtered through Whatman No. 1 filter paper, collected the supernatant, and stored at $4^{\circ} \mathrm{C}$ for nanoparticles synthesis.

2.3. Green Synthesis of Silver Nanoparticles. Typically, $10 \mathrm{~mL}$ of pure algal extract solution was mixed with aqueous solution of $90 \mathrm{~mL}$ of $1 \mathrm{mM}$ silver nitrate $\left(\mathrm{AgNO}_{3}\right)$ solution and kept in room temperature with constant stirring at $120 \mathrm{rpm}$. A color change of the solution was noted by visual inspection and UV-vis spectroscopy at different time and wavelength confirming the synthesis of silver nanoparticles.
2.4. Effect of $\mathrm{pH}$. The role of $\mathrm{pH}$ in the synthesis of silver nanoparticles was carried out by altering the $\mathrm{pH}$ of algal extract. The $\mathrm{pH}$ range was varied from $6.2,6.8,7.8$ and 8.4 by using analytical graded $0.1 \mathrm{~N}$ sodium hydroxide and $0.1 \mathrm{~N}$ hydrochloric acid standard solutions. The influence of $\mathrm{pH}$ on the synthesis process was analyzed by UV-vis spectrophotometer in the wavelength range of $380-600 \mathrm{~nm}$.

\subsection{Purification and Characterization of Synthesized Silver} Nanoparticles. The bioreduction of silver ions in aqueous solution using algae extract was monitored by double beam UV-vis spectrophotometer at different wavelengths from 320 to $700 \mathrm{~nm}$ (Perkin Elmer, Singapore). Green synthesized silver nanoparticles were purified by distilled water by repeated centrifugation at $10,000 \mathrm{rpm}$ for $15 \mathrm{~min}$. Crystalline nature of the purified silver nanoparticles was analyzed by XRD (Bruker, Germany, model: D8Advance) and particle morphology was characterized by Scanning Electron Microscope (Hitachi, Model: S-3400N). The functional biomolecules such as carboxyl groups present in the seaweed responsible for the silver nanoparticles formation were characterized by FT-IR (BrukerOptik GmbH Model No.-Tensor 27). The dried silver nanoparticles were compressed with $\mathrm{KBr}$ into thin pellets and measured at the wavelength range from 4000 to $400 \mathrm{~cm}^{-1}$.

\subsection{Antifungal Assay of Silver Nanoparticles}

2.6.1. Clinical Fungal Pathogens. The three fungal pathogenic strains used in the present study were isolated from clinical samples and identified from Microlabs, Vellore District, India, which were Aspergillus fumigatus, Candida albicans, and Fusarium sp.

2.6.2. Assay of Antifungal Activity. The antifungal activity of green synthesized silver nanoparticles against various fungal strains was assayed by Agar well diffusion method. The fungicidal effect of the silver nanoparticles could be assessed by the formation of zone around the well. $100 \mathrm{~mL}$ of sterilized Sabouraud Dextrose Agar medium was poured into three sterilized Petri dishes. The fungal strains were grown in Rose Bengal agar and their spores were mixed into the $10 \mathrm{~mL}$ sterile distilled water and swapped on the agar. Three wells of $5 \mathrm{~mm}$ diameter were prepared and loaded with silver nanoparticles at different concentrations $(30,60$, and $90 \mu \mathrm{L})$. The plates loaded with the fungal and silver nanoparticles were incubated at $37^{\circ} \mathrm{C}$. The antifungal activities against the fungal strains were confirmed by forming the zone around the wells and measured after 24 hrs of incubation. The zone of inhibition was expressed in $\mathrm{mm}$ in diameter. The experiments were repeated three times to find the standard deviation and standard error.

\section{Results and Discussion}

3.1. Visual and UV-Vis Spectrophotometer Analysis. Reduction of silver ions to silver nanoparticles was visually identified by color change from yellow to brown in the aqueous 




(a)

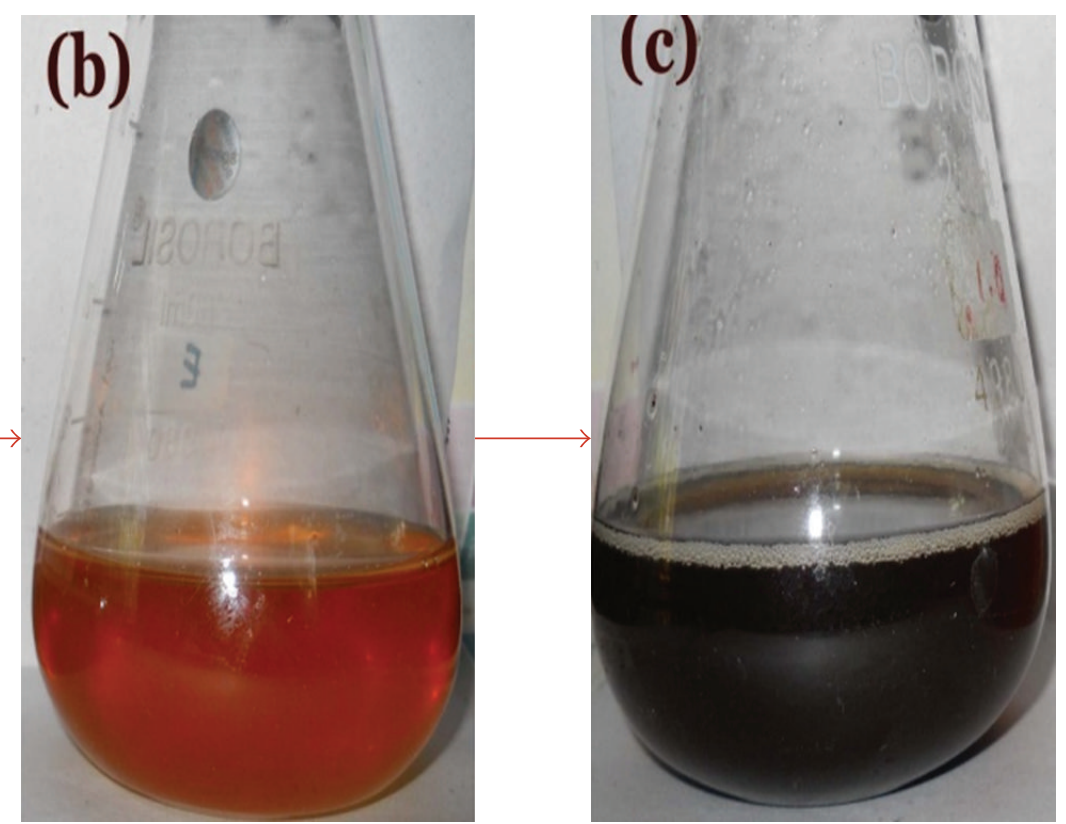

(b) (c)

FIGURE 1: Color change after the addition of algae extract with $1 \mathrm{mM} \mathrm{AgNO}_{3}$ indicates the formation of silver nanoparticles. (a) Initial color change, (b) $1 \mathrm{hr}$, (c) $32 \mathrm{hr}$.

solution of reaction mixture at $1 \mathrm{hr}$ incubation time (Figure 1). Brown formation occurred due to the oscillation of free electrons in the reaction mixture. The color change depended on the incubation time. The deep brown color for silver nanoparticles was attained at $32 \mathrm{hr}$ indicating that the increasing of color intensity is directly proportion to the time of incubation. Furthermore, the nanoparticles formation by the algal extract was confirmed by UV-vis spectroscopy at different wavelengths. Similarly, Chandran et al. [19] synthesized silver nanoparticles using Aloe vera extract taking $24 \mathrm{hr}$ of reaction time in the presence of ammonia which enhances the nanoparticles formation.

UV-vis spectroscopy analysis depends on the arising of color in the reaction due to the excitation of surface Plasmon resonance band in a reaction mixture and was recorded as different functional time. Figure 2 shows that, there is no peak were formed at the initial stage indicates that there is no synthesis of silver nanoparticles was observed. After $1 \mathrm{hr}$ of incubation time the surface Plasmon resonance band for silver nanoparticles was positioned at around $460 \mathrm{~nm}$ and the synthesis was steadily increasing with the increasing in time of reaction without change in the peak position. It shows no peak variation in their position with broad band indicates presence of polydispersed nanoparticles. The nanoparticles synthesis was completed at $64 \mathrm{~h}$ time of incubation.

3.2. Effect of $p H$. The $\mathrm{pH}$ of the reaction mixture plays an important role in the nanoparticles synthesis. At low pH 6.2, the color change of the reaction mixture was slower than that at high $\mathrm{pH}$ 8.4. The color intensity of the reduction process increased with the increase of the $\mathrm{pH}$ (Figure 3). Figure 4 shows the UV-vis spectra to analyze the $\mathrm{pH}$ impact on the



FIGURE 2: UV-vis spectra recorded the formation of nanoparticles in the reaction mixture of algae extract and $\mathrm{AgNO}_{3}$ at different time intervals showing the peak at $460 \mathrm{~nm}$.

nanoparticles synthesis. At lower pH 6.2 and 6.8, the broadened SPR band was shown at $460 \mathrm{~nm}$ indicating polydispersed nanoparticles formation. Broadening peaks occurred at lower $\mathrm{pH}$ due to the excitations of longitudinal Plasmon vibrations [20]. Broad band at low $\mathrm{pH}$ is due to the formation of anisotropic nanoparticles [21]. The narrow peak at higher $\mathrm{pH}$ that occurred is due to the formation of monodispersed and small-sized silver nanoparticles [22]. Lower $\mathrm{pH}$ suppresses nanoparticles formation and higher $\mathrm{pH}$ enhances the nanoparticles synthesis process. The high absorbance and narrow band was formed at $440 \mathrm{~nm}$ in the higher $\mathrm{pH}$. Similarly, some reports explained that $\mathrm{pH}$ plays an important role 




(a)

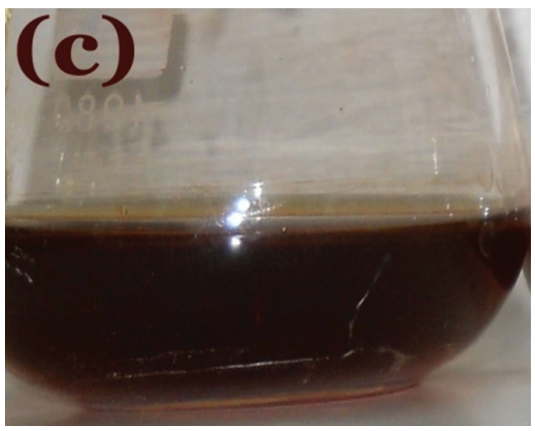

(c)

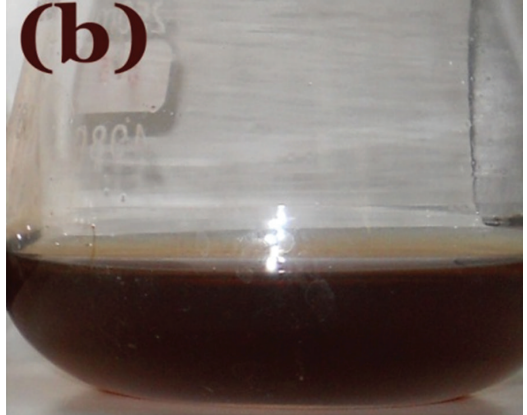

(b)

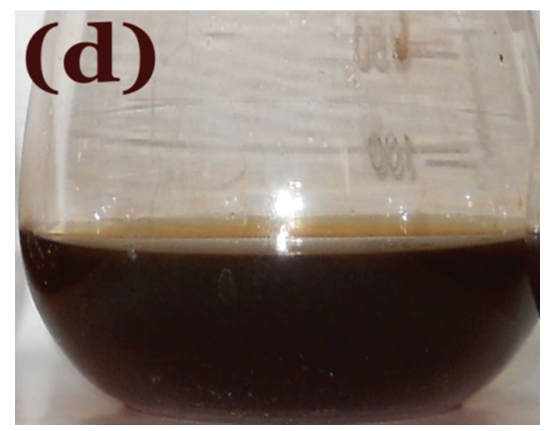

(d)

FIGURE 3: Color change variation at different pH levels (a) pH 6.2 (b) 6.8 (c) 7.8 (d) 8.4.

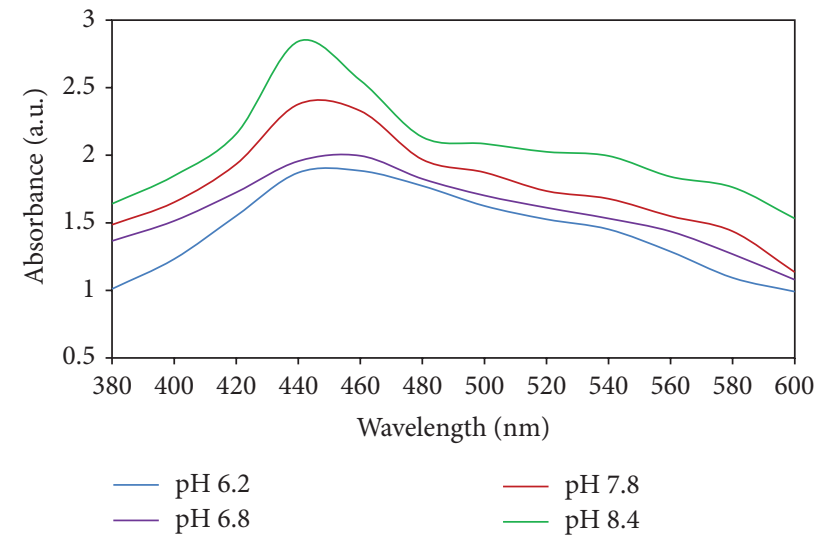

FIGURE 4: Effect of $\mathrm{pH}$ on the synthesis of silver nanoparticles shows that maximum synthesis occurred at high $\mathrm{pH}$.

in shape and size control synthesis process of silver nanoparticles. This is also in agreement with earlier reports that the addition of an alkaline ion in the reaction mixture is necessary to carry out the reduction of metal ions [23].

3.3. XRD Analysis. The crystalline structure of the silver nanoparticles was determined by XRD in the whole spectrum of $2 \theta$ values ranging from 10 to 80 . The green synthesized silver nanostructure by employing algae extract of $S$. longifolium was confirmed by the characteristic peaks observed in the XRD image (Figure 5). The four distinct diffraction peaks of the $2 \theta$ values of $38.27^{\circ}, 44.16^{\circ}, 65.54^{\circ}$, and $77.42^{\circ}$ could be



FIGURE 5: XRD spectrum of silver nanoparticles synthesized from $S$. longifolium extract shows crystalline structure of nanoparticles.

assigned the plane of (1 1 1 ), (2 00 ), (2 20$)$, and (3 11 ), respectively, indicating that the silver nanoparticles are fcc (face centered cubic) and crystalline in nature. The synthesized silver nanoparticles are compared with standard silver nitrate and pure silver particles which are published by Joint Committee on Powder Diffraction Standards (File nos. 04-0783 and 84-0713). The XRD clearly shows that the four distinct planes for the silver nanoparticles synthesized from algal extract of S. longifolium are highly crystallized and purified.

3.4. SEM Analysis. SEM image shows the morphologies of the algae mediated synthesized bionanoparticles at different 


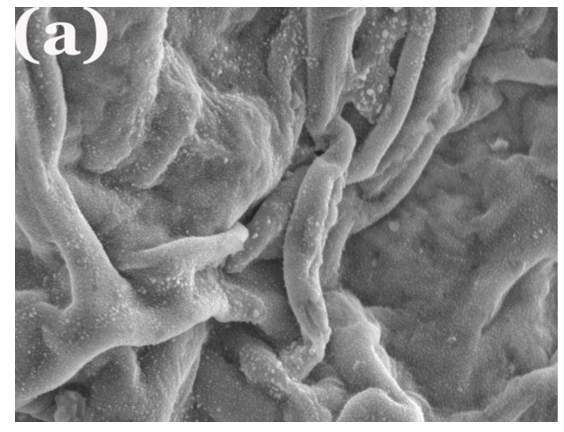

(a)

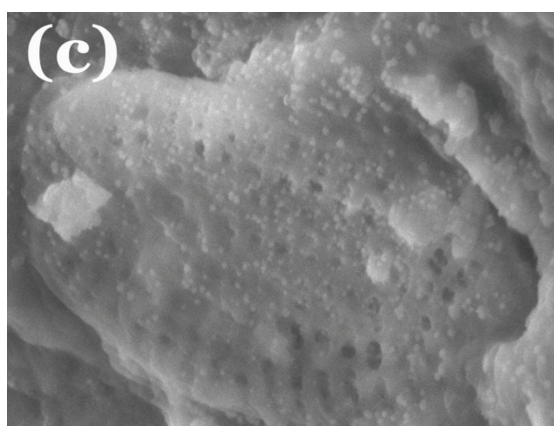

(c)

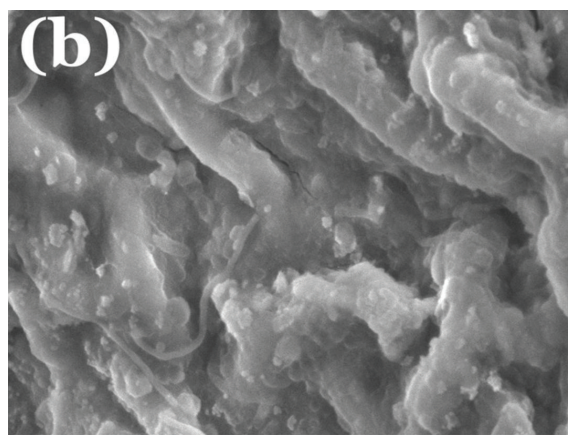

(b)

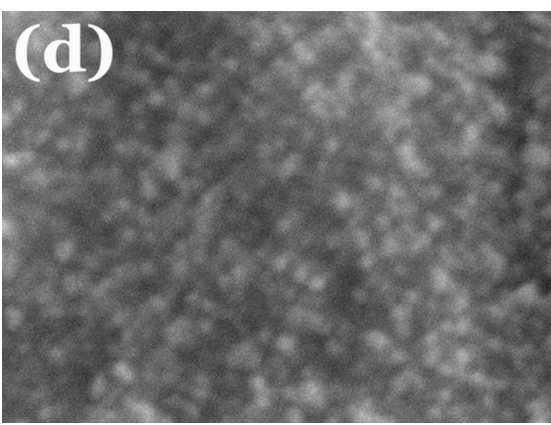

(d)

FIGURE 6: Scanning electron microscope image of silver nanoparticles synthesized from S. longifolium extract showing predominantly spherical shape nanoparticles on the surface of the cell at different magnifications: (a) $5 \mu \mathrm{m}$, (b) $3 \mu \mathrm{m}$, (c) $1 \mu \mathrm{m}$, and (d) $500 \mathrm{~nm}$.



FIGURE 7: TEM image of silver nanoparticles shows polydispersed synthesized silver nanoparticles.

magnifications (Figure 6). High density of silver nanoparticles is shown in the SEM image which is uniformly distributed on the surface of the cells of algae. The polydispersed silver nanoparticles were attached on the surface of the biomolecules of the algal cells. Silver nanoparticles adhered on the cells due to weakly dislodging of bound silver nanoparticles from the biomass and silver nitrate reaction mixture during preparation [24]. Similar results were obtained in the gold nanoparticles using algal extract of $S$. marginatum with the size ranging from 40 to $85 \mathrm{~nm}$ [25] and also by using the T. conoides algae [26]. It reveals the involvement of the polyphenolic or secondary capping agent in the nanoparticles formation.

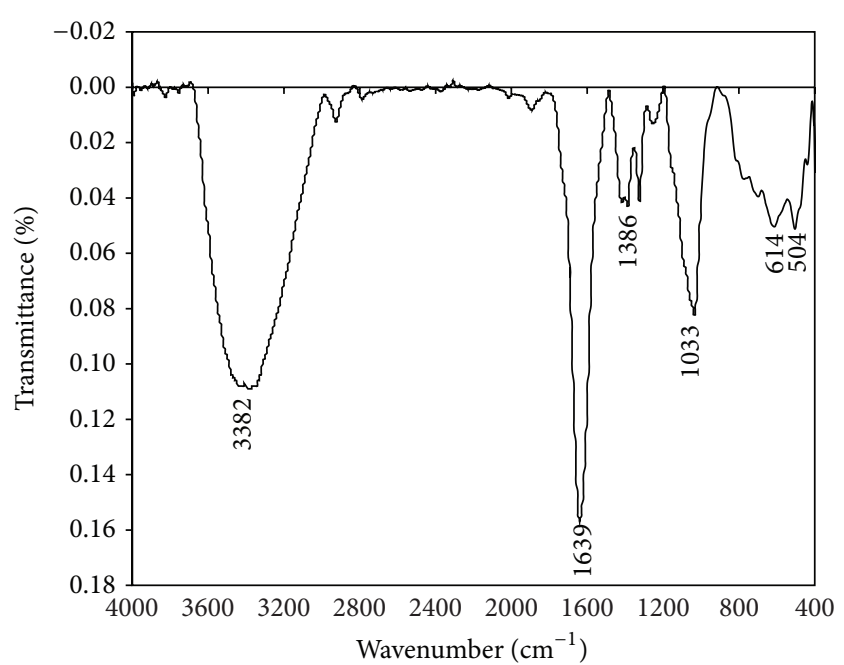

FIGURE 8: FTIR shows the functional groups associated with silver nanoparticles synthesized from extract of S. longifolium.

3.5. TEM Image of Silver Nanoparticles. The morphology of $S$. longifolium algae extract mediated synthesized silver nanoparticles was determined by TEM. The synthesized silver nanoparticles were formed predominantly spherical and some are truncated and ellipsoidal in the form of agglomerates. Some of the nanoparticles noted that the edges of the particles were smoother than the centers (marked by arrows) in Figure 7. The edges of nanoparticles were shown smoother 


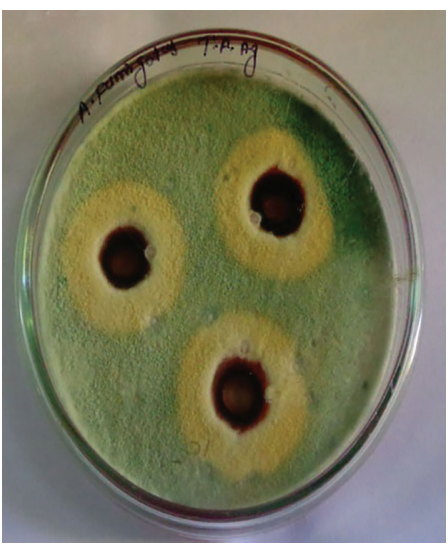

(a)



(b)

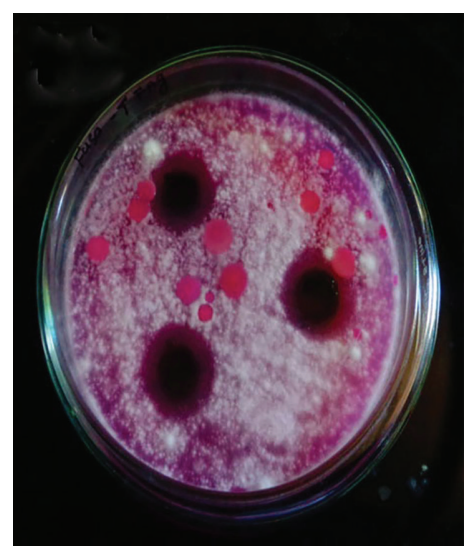

(c)

FIGURE 9: Antifungal activity of SNPs synthesized by using marine algae S. longifolium.

than the center indicating that the proteins in algal extract may cap the silver nanoparticles. Similarly, Ahmad et al. [27] suggested that proteins in basil plant are present among the particles and they adhered to their surfaces.

3.6. FTIR. FTIR was used to identify the biomolecules in $S$. longifolium responsible for the silver ions reduction and stabilization of reduced silver ions (Figure 8 ). The broad spectrum at $3382 \mathrm{~cm}^{-1}$ shows the $\mathrm{O}-\mathrm{H}$ bond stretching of alcohols and phenols. The narrow band at $1639 \mathrm{~cm}^{-1}(-\mathrm{NH}-\mathrm{C}=\mathrm{O})$ indicates the presence of $\mathrm{N}-\mathrm{H}$ bended primary amines. A weak band at $1386 \mathrm{~cm}^{-1}$ corresponds to asymmetrical stretching for nitro compounds. The absorption peak at $1033 \mathrm{~cm}^{-1}$ illustrates the presence of carboxylic acid functional group. The very weak bands were formed at 613 and $504 \mathrm{~cm}^{-1}$ due to the occurrence of vibrations of alkyl halides. FTIR revealed that soluble organic compounds or proteins in the extract may bind with silver ions and reduce the silver ions to nanoparticles. The carboxylic groups in the extract may enhance the stability of silver nanoparticles.

\subsection{Antifungal Activity of Algal Synthesized Silver Nanopar-} ticles. Nanostructured silver materials can be initialized in some potential applications in the field of bactericidal activities and they vigorously involve the fight against the pathogenic microbes causing dangerous disease. The green synthesized silver nanoparticles exhibited excellent antibacterial activity against pathogenic fungi such as A. fumigatus, Candida albicans, and Fusarium sp. Silver could be used as an antibacterial agent for many infectious diseases at ancient time and before the emergence of antibiotics [28]. In this study, the antifungal activity of S. longifolium mediated synthesized silver nanoparticles against harmful pathogenic fungi at different concentrations $(50,100$, and $150 \mu \mathrm{L})$ was carried out. Table 1 shows that with the increase in the concentration of silver nanoparticles, the zone of inhibition increased. So the zone formation around the well is directly proportional to the concentration of silver nanoparticles (Figure 9).
TABLE 1: Antifungal activity of silver bionanoparticles against pathogenic fungi.

\begin{tabular}{lccc}
\hline \multirow{2}{*}{ Pathogenic fungi } & \multicolumn{3}{c}{ Zone of inhibition (mm in diameter) } \\
& $50 \mu \mathrm{L}$ & $100 \mu \mathrm{L}$ & $150 \mu \mathrm{L}$ \\
\hline Aspergillus fumigatus & $11.17 \pm 0.152$ & $12.07 \pm 0.120$ & $13.10 \pm 0.130$ \\
Candida albicans & $11.20 \pm 0.256$ & $13.87 \pm 0.134$ & $14.20 \pm 0.152$ \\
Fusarium sp. & $18.10 \pm 0.208$ & $20.23 \pm 0.186$ & $22.03 \pm 0.033$ \\
\hline
\end{tabular}

\pm Standard deviation.

Silver nanoparticles highly form the zone against Fusarium sp. $(22.03 \pm 0.033) \mathrm{mm}$ at the concentration of $150 \mu \mathrm{L}$. Minimum zone inhibition was observed against $A$. fumigates $(13.10 \pm 0.130) \mathrm{mm}$.

The mechanism of antifungal activity of silver nanoparticles was not fully known. A few of the literature illustrated the possible mechanism of antifungal activity. Antifungal activity depends on the size and shape of the silver nanoparticles. Small size nanoparticles have large surface area ensuring the inhibition of microbial growth. Spherical shape with sizereduced silver ions has the increased contact area so that it can eliminate the bacterial growth. Activity of silver nanoparticles has similar effects as silver ions [29]. Positively charged silver ions may attach with negatively charged cell membranes of microbes by electrostatic attraction [30]. Silver nanoparticles form the pits in the cell wall and damage the cell permeability [31] and induce the proton leakage caused by ROS in the membrane $[32,33]$ resulting in cell death. Kim et al. [34] demonstrated that silver nanoparticles inhibit the conidial germination on fungi. Finally, the silver nanoparticles have a great potential to control the spore producing fungi.

\section{Conclusion}

In conclusion, this present study stated the green mediated synthesis of silver nanoparticles under optimized parameters using the extract of enormously available algae S. longifolium. The broad peak was observed under UV-vis spectra at $460 \mathrm{~nm}$ for silver nanoparticles. Highly synthesis and spherical shape 
nanoparticles were obtained at higher $\mathrm{pH}$ confirmed by TEM. Crystalline structure of nanoparticles was identified by XRD. Purity and component of silver nanoparticles were confirmed by EDX. S. longifolium extract mediated synthesized silver nanoparticles show high antifungal activity that can be used therapeutically in biomedical applications.

\section{Conflict of Interests}

The authors declare that there is no conflict of interests regarding the publication of this paper.

\section{Acknowledgments}

The authors gratefully acknowledge STIC, Cochin for providing XRD and EDX, IIT Bombay for TEM facility, and DST for FIST grant (Ref. no. S/FST/ESI-101/2010).

\section{References}

[1] A. Jensen, "Present and future needs for algae and algal products," Hydrobiologia, vol. 260-261, no. 1, pp. 15-23, 1993.

[2] A. K. Semesi, "Coastal resource of Bagamoyo District, Tanzania," Trends in Plant Science, vol. 11, pp. 517-533, 2000.

[3] M. M. Chandraprabha, R. Seenivasan, H. Indu, and S. Geetha, "Biochemical and nanotechnological studies in selected seaweeds of Chennai Coast," Journal of Applied Pharmaceutical Science, vol. 2, no. 11, pp. 100-107, 2012.

[4] R. Lavanya and N. Veerappan, "Antibacterial potential of six seaweeds collected from gulf of mannar of Southeast Coast of India," Advances in Biological Research, vol. 5, no. 1, pp. 38-44, 2011.

[5] S. Ravikumar, L. Anburajan, G. Ramanathan, and N. Kaliaperumal, "Screening of seaweed extracts against antibiotic resistant post operative infectious pathogens," Seaweed Research and Utilization, vol. 24, no. 1, pp. 95-99, 2002.

[6] A. Ayesha, H. Hira, V. Sultana, J. Ara, and S. Ehteshamul-Haque, "In vitro cytotoxicity of seaweeds from Karachi coast on brine shrimp," Pakistan Journal of Botany, vol. 42, no. 5, pp. 35553560, 2010.

[7] K. Vijayaraghavan, T. T. Teo, R. Balasubramanian, and U. M. Joshi, "Application of Sargassum biomass to remove heavy metal ions from synthetic multi-metal solutions and urban storm water runoff," Journal of Hazardous Materials, vol. 164, no. 2-3, pp. 1019-1023, 2009.

[8] M. Amin, F. Anwar, M. R. S. A. Janjua, M. A. Iqbal, and U. Rashid, "Green synthesis of silver nanoparticles through reduction with Solanum xanthocarpum L. berry extract: characterization, antimicrobial and urease inhibitory activities against Helicobacter pylori," International Journal of Molecular Sciences, vol. 13, pp. 9923-9941, 2012.

[9] P. Mohanpuria, N. K. Rana, and S. K. Yadav, "Biosynthesis of nanoparticles: technological concepts and future applications," Journal of Nanoparticle Research, vol. 10, no. 3, pp. 507-517, 2008.

[10] T. Kubik, K. Bogunia-Kubik, and M. Sugisaka, "Nanotechnology on duty in medical applications," Current Pharmaceutical Biotechnology, vol. 6, no. 1, pp. 17-33, 2005.

[11] S. Sinha, I. Pan, P. Chanda, and S. K. Sen, "Nanoparticles fabrication using ambient biological resources," Journal of Applied Biosciences, vol. 19, pp. 1113-1130, 2009.
[12] L. Rastogi and J. Arunachalam, "Sunlight based irradiation strategy for rapid green synthesis of highly stable silver nanoparticles using aqueous garlic (Allium sativum) extract and their antibacterial potential," Materials Chemistry and Physics, vol. 129, no. 1-2, pp. 558-563, 2011.

[13] A. R. Shahverdi, S. Minaeian, H. R. Shahverdi, H. Jamalifar, and A.-A. Nohi, "Rapid synthesis of silver nanoparticles using culture supernatants of Enterobacteria: a novel biological approach," Process Biochemistry, vol. 42, no. 5, pp. 919-923, 2007.

[14] K. C. Bhainsa and S. F. D'Souza, "Extracellular biosynthesis of silver nanoparticles using the fungus Aspergillus fumigatus," Colloids and Surfaces B, vol. 47, no. 2, pp. 160-164, 2006.

[15] K. B. Narayanan and N. Sakthivel, "Coriander leaf mediated biosynthesis of gold nanoparticles," Materials Letters, vol. 62, no. 30, pp. 4588-4590, 2008.

[16] G. Singaravelu, J. S. Arockiamary, V. G. Kumar, and K. Govindaraju, "A novel extracellular synthesis of monodisperse gold nanoparticles using marine alga, Sargassum wightii Greville," Colloids and Surfaces B, vol. 57, no. 1, pp. 97-101, 2007.

[17] T. A. Davis, B. Volesky, and A. Mucci, "A review of the biochemistry of heavy metal biosorption by brown algae," Water Research, vol. 37, no. 18, pp. 4311-4330, 2003.

[18] M. Gericke and A. Pinches, "Microbial production of gold nanoparticles," Gold Bulletin, vol. 39, no. 1, pp. 22-28, 2006.

[19] S. P. Chandran, M. Chaudhary, R. Pasricha, A. Ahmad, and M. Sastry, "Synthesis of gold nanotriangles and silver nanoparticles using Aloe vera plant extract," Biotechnology Progress, vol. 22, no. 2, pp. 577-583, 2006.

[20] P. V. Kamat, M. Flumiani, and G. V. Hartland, "Picosecond dynamics of silver nanoclusters: photoejection of electrons and fragmentation," Journal of Physical Chemistry B, vol. 102, no. 17, pp. 3123-3128, 1998.

[21] D. Philip, "Green synthesis of gold and silver nanoparticles using Hibiscus rosasinensis," Physica E, vol. 42, no. 5, pp. 14171424, 2010.

[22] T. P. Amaladhas, S. Sivagami, T. A. Devi, N. Ananthi, and S. P. Velammal, "Biogenic synthesis of silver nanoparticles by leaf extract of Cassia angustifolia," Advances in Natural Sciences, vol. 3, no. 7, Article ID 045006, 2012.

[23] R. Sanghi and P. Verma, "Biomimetic synthesis and characterisation of protein capped silver nanoparticles," Bioresource Technology, vol. 100, no. 1, pp. 501-504, 2009.

[24] M. Sastry, A. Ahmad, M. Islam Khan, and R. Kumar, "Biosynthesis of metal nanoparticles using fungi and actinomycete," Current Science, vol. 85, no. 2, pp. 162-170, 2003.

[25] F. A. A. Rajathi, C. Parthiban, V. Ganesh Kumar, and P. Anantharaman, "Biosynthesis of antibacterial gold nanoparticles using brown alga, Stoechospermum marginatum (kützing)," Spectrochimica Acta A, vol. 99, pp. 166-173, 2012.

[26] K. Vijayaraghavan, A. Mahadevan, M. Sathishkumar, S. Pavagadhi, and R. Balasubramanian, "Biosynthesis of $\mathrm{Au}(0)$ from $\mathrm{Au}(\mathrm{III})$ via biosorption and bioreduction using brown marine alga Turbinaria conoides," Chemical Engineering Journal, vol. 167, no. 1, pp. 223-227, 2011.

[27] N. Ahmad, S. Sharma, M. K. Alam et al., "Rapid synthesis of silver nanoparticles using dried medicinal plant of basil," Colloids and Surfaces B, vol. 81, no. 1, pp. 81-86, 2010.

[28] H. J. Klasen, "Historical review of the use of silver in the treatment of burns. I: early uses," Burns, vol. 26, no. 2, pp. 117-130, 2000 . 
[29] S. Pal, Y. K. Tak, and J. M. Song, "Does the antibacterial activity of silver nanoparticles depend on the shape of the nanoparticle? A study of the gram-negative bacterium Escherichia coli," Applied and Environmental Microbiology, vol. 73, no. 6, pp. 17121720, 2007.

[30] I. Sondi and B. Salopek-Sondi, "Silver nanoparticles as antimicrobial agent: a case study on E. coli as a model for Gramnegative bacteria," Journal of Colloid and Interface Science, vol. 275, no. 1, pp. 177-182, 2004.

[31] M. Raffi, F. Hussain, T. M. Bhatti, J. I. Akhter, A. Hameed, and M. M. Hasan, "Antibacterial characterization of silver nanoparticles against E. coli ATCC-15224," Journal of Materials Science and Technology, vol. 24, no. 2, pp. 192-196, 2008.

[32] P. Dibrov, J. Dzioba, K. K. Gosink, and C. C. Häse, "Chemiosmotic mechanism of antimicrobial activity of Ag+ in Vibrio cholerae," Antimicrobial Agents and Chemotherapy, vol. 46, no. 8, pp. 2668-2670, 2002.

[33] S. H. Dehkordi, F. Hosseinpour, and A. E. Kahrizangi, "An in vitro evaluation of antibacterial effect of silver nanoparticles on Staphylococcus aureus isolated from bovine subclinical mastitis," African Journal of Biotechnology, vol. 10, no. 52, pp. 1079510797, 2011.

[34] S. W. Kim, K. S. Kim, K. Lamsal et al., "An in vitro study of the antifungal effect of silver nanoparticles on oak wilt pathogen Raffaelea sp," Journal of Microbiology and Biotechnology, vol. 19, no. 8, pp. 760-764, 2009. 



Submit your manuscripts at http://www.hindawi.com
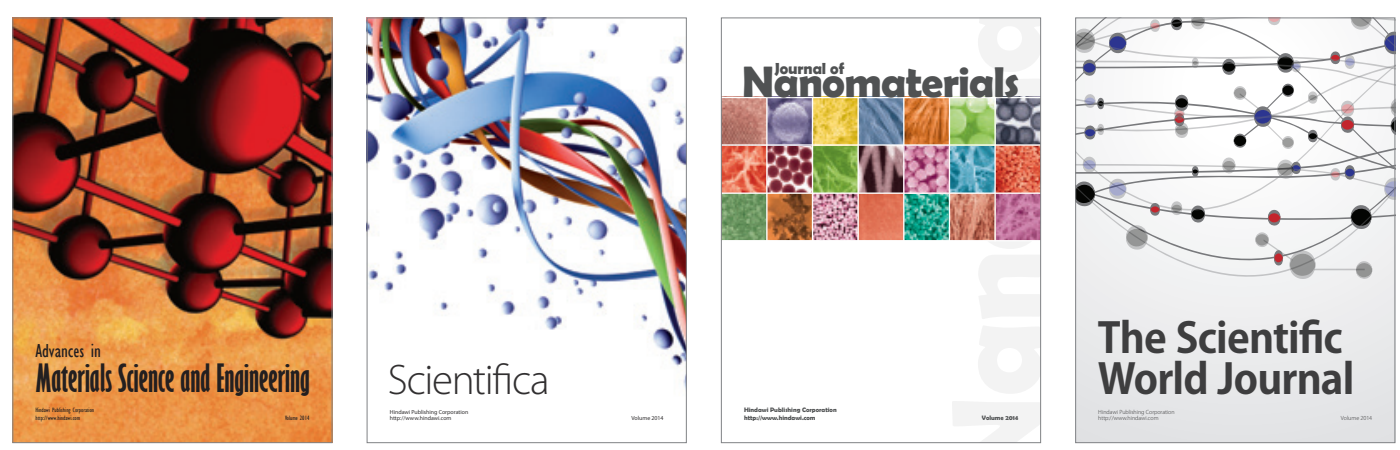

\section{The Scientific World Journal}
